\title{
PROSPECÇÃO DE CENÁRIOS E MONITORAMENTO INFORMACIONAL COMO FERRAMENTAS DE INTELIGÊNCIA COMPETITIVA PARA O PLANEJAMENTO DE POLÍTICAS PÚBLICAS NO ESTADO DE GOIÁS
}

\section{PROSPECCIÓN ESCENARIOS Y MONITOREO DE INFORMACIÓN COMO HERRAMIENTAS DE INTELIGENCIA COMPETITIVA PARA LA PLANIFICACIÓN DE POLÍTICA EN EL ESTADO DE GOIÁS}

\begin{abstract}
Arielle Lopes de Almeida - ariellelopes@yahoo.com.br Especialista em Avaliação de Ambientes Informacionais pela Universidade Federal de Goiás (UFG). Bibliotecária da Pontifícia Universidade Católica de Goiás (PUC).

João de Melo Maricato - jmmaricato@gmail.com Doutor em Ciência da Informação pela Universidade de São Paulo

(USP). Professor da Universidade Federal de Goiás (UFG).
\end{abstract}

\section{RESUMO}

Introdução: A inteligência estratégica pode ser vista como um processo informacional contínuo que visa identificar relações e conexões para construir cenários futuros de forma a minimizar riscos e ações irrefletidas. Reconhece a importância de um ambiente informacional voltado à obtenção, criação, compartilhamento e internalização do conhecimento, inclusive no setor público. Objetivo: Assim, o objetivo a pesquisa é identificar as atividades de inteligência que estão sendo utilizadas para o planejamento do estado de Goiás.

Metodologia: Utiliza como procedimentos metodológicos a pesquisa bibliográfica e entrevista. Trata-se de estudo de caso, com apoio em uma pesquisa qualitativa descritiva. Identifica e analisa as atividades de inteligência utilizadas nas secretarias de Gestão e Planejamento, Indústria e Comércio e Segurança Pública.

Resultados: Foi possível identificar que no estado de Goiás não existe um processo unificado de prospecção e monitoramento. Existem investimentos em 
atividades de inteligência, porém, estes não estão efetivamente implementadas ou bem gerenciadas.

Conclusão: Apesar de a inteligência estratégica servir como orientadora do processo de prospecção e monitoramento. Indica os principais cenários a serem acompanhados, na administração pública, no estado de Goiás, existem lacunas na sua utilização.

Palavras-Chave: Inteligência estratégica. Planejamento Governamental. Estado de Goiás. Ambiente informacional. Prospecção de cenários. Monitoramento informacional.

\section{INTRODUÇÃO}

$\mathrm{Na}$ ambiência do mundo atual, muitas vezes, parece que o estado, política e poder são conceitos atrelados a peças de um jogo de adivinhação, muito pouco pautado em estratégias. Programas, planos e objetivos governamentais são direcionados muito fortemente por interesses políticos individuais. O poder parece ser dado aos que correm contra o tempo, na tentativa de atender a urgência (AUN, 2003, p. 5657).

Apesar desse cenário, considera-se que as atividades inteligência competitividade têm (ou deveria ter) papel fundamental para o estado, pois pode alimentar todo o processo de planejamento com dados, informação e conhecimento. A partir da seleção, avaliação e interpretação de informações, a organização (inclusive a pública), pode transforma-se em um ambiente informacional possibilitando 0 aprendizado contínuo.

A maioria dos estudos relacionados à Inteligência Competitiva (IC) está associada às empresas privadas. Poucos são os estudos que aplicam as metodologias e técnicas de análise competitiva para organizações públicas ou sem fins lucrativos. Isso ocorre, em certa medida, porque tais organizações estão estruturadas e trabalham de maneira diferente das organizações privadas. Diante das diferenças torna-se difícil utilizar das metolologias de IC ao setor público. Os 
indicadores dessas organizações normalmente são mais subjetivos quando comparados ás empresas privadas. Alguns indicadores e conceitos clássicos como concorrência, competição, negócios, preços e cliente normalmente são diferentes dentre essas organizações e difíceis de serem medidos.

São relativamente poucos os estudos que explicitamente buscam aplicar as metodologias e técnicas da IC ao setor público no Brasil. A produção científica está dispersa principalmente em relatórios, teses e dissertações e trabalhos apresentados em eventos. Alguns exemplos dos poucos trabalhos publicados em periódicos científicos são os de Cristo (2014), Guedes e Cândido (2010), Macedo, Rodrigues e Silveira (2011). Isso demostra a fragilidade da pesquisa sobre IC na esfera pública e necessidade de ampliação das pesquisas no setor.

Apesar dessas diferentes, entende-se que os conceitos, ferramentas, metodologias podem ser efetivamente e eficazmente utilizados nas organizações do setor público, tais como agências governamentais, universidades, organizações comunitárias e sociais, organizações estaduais, municipais ou locais. O setor público necessita de conhecimento diante de cenários tão competitivos e interativos (FLEISHER, 2001).

Diante desse contexto, este artigo tem por objetivo identificar as atividades de inteligência que estão sendo utilizadas para o planejamento do estado de Goiás. Como metodologia, foi utilizado a pesquisa bibliográfica, a partir de uma análise de IC e ambiente informacional, principalmente no que tange as atividades de prospecção de cenários e monitoramento informacional. Realizou-se, também, levantamento $\mathrm{e}$ análise das atividades de inteligência para o planejamento de estado de Goiás, por meio de entrevistas realizadas nas secretarias de Gestão e Planejamento, Indústria e Comércio, e, Segurança Pública do estado. 
De forma complementar, analisaram-se documentos disponíveis nos sites dessas secretarias, com intuito de identificar elementos que podem ser enquadrados como ações de monitoramento informacional e IC, mesmo que não tenham sido explicitadas nas entrevistas. Considera-se relevante compreender como o estado está atuando na perspectiva de realizar atividades de planejamento a partir dos conceitos e atividades de inteligência e monitoramento informacional.

\section{INTELIGÊNCIA COMPETITIVA}

Em razão das necessidades de assessoramento estratégico militar se desenvolveu a atividade de Inteligência. Atualmente, ainda é pouco levada em consideração no setor público, mesmo que o Estado possua legislação acerca da organização e funcionamento do Sistema Brasileiro de Inteligência e considere a inteligência como "atividade de obtenção e análise de dados e informações e de produção e difusão de conhecimentos, dentro e fora do território nacional, relativos a fatos e situações de imediata ou potencial influência sobre 0 processo decisório" (BRASIL, 2002).

$\mathrm{Na}$ condição de exercer esta influência sobre o processo decisório, Platt (1974, p. 30) definiu Inteligência como "um termo específico e significativo, derivado da informação, informe, fato ou dado que foi selecionado, avaliado, interpretado e, finalmente, expresso de forma tal que evidencie sua importância para determinado problema". Assim, o serviço inteligência deve motivar a administração pública, tendo em vista o aperfeiçoamento de seus serviços e seu posicionamento em relação ao desenvolvimento tecnológico e à nova ordem internacional (QUEYRAS, QUONIAM, 2006, p. 94).

Pode-se definir a IC como um serviço de inteligência voltado para organizações, "uma atividade especializada, permanentemente exercida com o objetivo de produzir informação acionável (Inteligência) 
de interesse de um determinado ator e da salvaguarda desta informação contra ações adversas de qualquer natureza." (MARCIAL, 2011, p. 36). Para tanto, deve investigar $\mathrm{o}$ ambiente onde a empresa (ou organização) está inserida, com o propósito de descobrir oportunidades e reduzir os riscos, bem como diagnosticar o ambiente interno, visando o estabelecimento de estratégias de ação a curto, médio e longo prazo (VALENTIM et al., 2003).

Assim, a IC tem como foco a identificação de vantagens competitivas, a velocidade e objetividade de sua utilização e a simplicidade de seu funcionamento, possibilitando a utilização da informação relevante como insumo fundamental para a proposição de estratégias e para a tomada de decisão (ROEDEL, 2006, p. 85).

É importante lembrar, também, que "a inteligência competitiva pode se definir como um processo de aprendizado motivado pela competição, fundado sobre a informação, permitindo esta última a otimização da estratégia corporativa em curto e em longo prazo." (TARAPANOFF, 2006, p. 26). E, que é um processo contínuo cuja "maior complexidade está no fato de estabelecer relações e conexões de forma a gerar inteligência para a organização, na medida em que cria estratégias para cenários futuros e possibilita tomada de decisão de maneira mais segura e assertiva." (VALENTIM, 2002).

Outro aspecto relevante da IC é entendê-la como um processo composto, apoiado por elementos essenciais como a cultura e a comunicação organizacional, as atividades de prospecção e monitoramento informacional $e$ as tecnologias de informação e comunicação. Referindo-se, também, a um modelo de gestão sistêmico que se transforma a cada momento, buscando evoluir de um estado para outro supostamente melhor (VALENTIM, 2007, p. 22).

O trabalho do profissional de Inteligência envolve a análise de dados, dos resultados. Sendo assim, faz parte das atribuições do profissional de inteligência: "a produção de informações que evitem que 
as organizações sejam surpreendidas; a análise de impactos das informações produzidas sobre o futuro e a proposição de ações; e a produção de informações que auxilie a elaboração do planejamento estratégico da organização e de planos, inclusive os de contingência". (MARCIAL, 2011, p. 234).

Para tanto, os profissionais de inteligência "são treinados para juntar fragmentos de informação e integrá-los para compreender o todo." (MARCIAL, 2011, p. 206) e "antecipar as mudanças que ocorrerão no ambiente, evitando que a organização seja surpreendida." (MARCIAL, 2011, p. 206). Ou seja, o profissional de Inteligência deve alertar sobre a exigência de movimentos consolidados que se estenderão no futuro, podendo trazer oportunidades ou riscos para a organização. Esse processo inicia-se com a identificação das principais questões ligadas a sua área de atuação. Em seguida, devem-se verificar quais as variáveis apresentam comportamento tendencioso, mantendo, assim, a organização informada. (MARCIAL, 2011, p. 184).

Para entendermos o processo para obtenção de IC pode-se recorrer a Valentim (2002), que apresenta sete passos para seu funcionamento contínuo:

1. Identificar os "nichos" de inteligência internos e externos à organização;

2. Prospectar, Acessar e Coletar os dados, informações e conhecimento produzidos internamente e externamente à organização;

3. Selecionar e Filtrar os dados, informações e conhecimento relevantes para as pessoas e para a organização;

4. Tratar e Agregar Valor aos dados, informações e conhecimento mapeados e filtrados, buscando linguagens de interação usuário / sistema;

5. Armazenar através de Tecnologias de Informação os dados, informações e conhecimento tratados, buscando qualidade e segurança;

6. Disseminar e transferir os dados, informações e conhecimento através de serviços e produtos de alto valor agregado para o desenvolvimento competitivo e inteligente das pessoas e da organização;

7. Criar mecanismos de feed-back da geração de novos dados, informações e conhecimento para a retroalimentação do sistema. (VALENTIM, 2002). 
Marcial (2001, p. 240) acrescenta que profissionais de inteligência devem: monitorar permanentemente o ambiente; manter redes de especialistas; conhecer os métodos e as "ferramentas" da prospectiva; saber identificar e classificar as sementes de futuro; analisar os estudos de futuro e identificar os impactos na organização; propor ações e construir planos de contingencia; ter conhecimento aprofundado e monitorar sistematicamente os principais agentes de mudança; Nunca se esquecer de que o futuro é múltiplo e incerto (MARCIAL, 2011, p. 240).

\section{AMBIENTE INFORMACIONAL}

As organizações atuam em um ambiente com grandes instabilidades, mudanças e incertezas. A partir das teorias de IC podese falar que a maior arma para a um diferencial competitivo, ou até para a sobrevivência das organizações (públicas ou privadas), é desenvolver um ambiente com capacidade de aprendizagem continua. Para tanto, a criação de um ambiente informacional voltado a obtenção, criação, compartilhamento e internalização do conhecimento torna-se fundamental.

Segundo Davenport (2001) o ambiente informacional está arraigado no ambiente organizacional, e ambos são afetados pelo ambiente externo da empresa. Assim, é importante um sistema organizacional estruturado, visto como um conjunto de fatores influencia a gestão das organizações, atuando de forma integrada para transformar insumos em resultados. Esse sistema é composto pelo ambiente, pessoas, tecnologia, processos gerenciais e cultura, e qualquer mudança em um, implica alterações nos demais (SILVA, 2006, p. 196).

Davenport (2001) apresenta seis dimensões do ambiente informacional: 
Estratégia da informação - significa a possibilidade de fazer escolhas, num processo continuo, em desenvolvimento, de definir e redefinir as diretrizes de uma organização, sem poder antecipar o futuro.

Política da informação - diversos modelos possíveis para o gerenciamento e o uso da informação, que é influenciado pelo poder, pela política e pela economia da organização.

Cultura e comportamento relacionados à informação comportamento informacional quanto o modo como os indivíduos lidam com a informação, incluindo a busca, o uso, a alteração, a troca, o acúmulo e 0 ato de ignorar a informação. Este padrão de comportamento, valores e crenças é o que forma a cultura de uma empresa.

Equipe de informação - são os profissionais que agregam valor às informações aos usuários e desempenharão papel de condensar, contextualizar, aconselhar o melhor estilo e escolher os meios corretos de apresentação da informação.

Processos de gerenciamento da informação - tratam-se de um conjunto estruturado de atividades que incluem o modo como as empresas obtêm, distribuem e usam a informação e o conhecimento.

Arquitetura da informação - seu uso vem do fato de que as informações encontram-se dispersas, provem de muitas fontes e são utilizadas para diversas finalidades, portanto, se constituí de uma série de ferramentas que adaptam os recursos às necessidades da informação, conectando os comportamentos, os processos, o pessoal e outros aspectos da empresa como os métodos, a estrutura e o espaço físico.

Choo (2003) apresenta a necessidade de uma organização possuir um sistema de uso da informação baseada em três processos: a criação de significado, construção do conhecimento e tomada de decisões, integrando um clico de interpretação, aprendizado e ação. 
Assim, o conhecimento organizacional manifesta-se de maneira a ampliar as capacidades e opções da organização.

Apesar de não existir um modelo totalmente adaptado a uma organização, a estruturação de um modelo de ambiente informacional tem por finalidade melhorar o desempenho das empresas. No entanto, na administração pública possui finalidade e atuação complexa, ao abordar de temas relevantes para a sociedade. A organização pública deve, assim, tratar de maneira adequada e com rapidez desafios os desafios inesperados. Assim como as empresas privadas, devem estar preparadas para atuarem como parceiros na elaboração e implementação de políticas públicas, promover a inserção social, a redução das desigualdades e a qualidade de vida, bem como criar uma sociedade competitiva na economia regional e global (BATISTA, 2006. p. 188).

Para Wagner (2003), organizações públicas e sem fins lucrativos precisam realizar de maneira análoga o mesmo tipo de planejamento estratégico que as organizações com fins lucrativos, incluindo a análise do meio ambiente. Dentre os aspectos, são destacados pelo autor: ambiente informacional interno (necessidades, desejos, interesses internos dos envolvidos, incluindo suporte político, diretores, gestores e pessoal de apoio); Ambiente de mercado (grupos ou outras organizações relacionadas diretamente ao trabalho da organização; incluindo clientes, intermediários, fornecedores, pessoal de suporte). A IC deve monitorar tendências e mudanças necessárias, percepções, preferências e satisfações; Ambiente público (outros grupos ou organizações que tem interesse no grupo foco, incluindo público local, públicos ativistas, público geral, públicos de mídia, público regulamentador ou político, como, por exemplo, tomadores de decisão políticas. Tendências e mudanças nas percepções desses grupos devem ser monitoradas e analisadas); Ambiente competitivo (competição pela atenção dos fundadores e fidelização dos 
consumidores, incluindo as atividades dos concorrentes. As ações desses concorrentes devem ser monitoradas e analisadas); Macro ambiente (demográfico, tecnológico, político e forças sociais devem ser monitoradas e analisadas.

\subsection{Cenários Prospectivos}

Um dos principais métodos de prospecção utilizados nas atividades de Inteligência são os cenários prospectivos, principalmente, quando o assunto tratado é de grande incerteza, pois, são "construídos para apoiar o processo de planejamento estratégico de longo prazo e servem como orientadores do processo de monitoramento, indicando as principais questões e atores e serem acompanhadas." (MARCIAL, 2011, p. 40).

Nesse sentido, a prospectiva por cenários é o insumo básico do planejamento estratégico. Mediante a construção de cenários, são identificados os desafios do futuro e, após um processo de decisão estratégica, obtidos os cenários preceptores, que indicarão o futuro desejado. Assim, utiliza-se esta técnica para descrever, a partir da montagem do quebra-cabeça de variáveis identificadas, situações futuras e suas possíveis inter-relações, orientando e consolidando o processo de tomada de decisão (TARAPANOFF, 1995, p. 30).

Um cenário é definido por Bluet e Zemor (1970 apud GODET, 1987, p. 70) como "conjunto formado pela descrição de uma situação futura e do encaminhamento dos acontecimentos que permitem passar da situação de origem à situação futura." Godet (1987, p. 70) acrescenta que este conjunto de acontecimentos deve apresentar certa coerência. Cenário, contudo, não é sinônimo de adivinhação, nem de profecia, é apenas um quadro de referência, um conjunto de premissas e hipóteses, um consenso dos administradores para a construção do plano estratégico (COSTA, 2007. p. 92). 
Assim, cenário é um conjunto consistente de premissas consideradas plausíveis, funcionando como pano de fundo para atividades de uma instituição. Ele condiciona as atividades, as perspectivas de crescimento, de rentabilidade e de resultados, a vulnerabilidade e até a sobrevivência da organização (COSTA, 2007. p. 92).

Descritas as possibilidades de futuro, o profissional de Inteligência analisa as implicações de cada um dos cenários possíveis, identifica oportunidades e ameaças e indica qual dos movimentos seria o mais provável em função do estudo de Inteligência. E é recomendável que sugestões de ações sejam elaboradas tanto para o movimento considerado mais provável, quanto para todas as demais possibilidades de movimento futuro (MARCIAL, 2011, p. 44).

Diante as possibilidades dos cenários, Godet (1993, p. 71) faz a distinção de três tipos: o cenário de referência, que corresponde ao cenário mais provável; o cenário contrastado, que corresponde ao cenário realizável; e o cenário desejável, como o cenário possível e não necessariamente realizável.

Como os cenários podem gerar incertezas na seleção da estratégia, Michel Porter (1989, p. 436) apresenta cinco métodos para lidar com esta incerteza, não sendo necessariamente empregados nesta sequência e podendo ser combinados:

1. Apostar no cenário mais provável;

2. Apostar no "melhor" cenário, ou seja, onde possa estabelecer a vantagem competitiva;

3. Garantir a sobrevivência da organização em todos os cenários;

4. Preservar flexibilidade, ou seja, desenvolver estratégias que facilitem ajustes caso ocorram mudanças nos cenários;

5. Influenciar a ocorrência do melhor cenário, que propicie a construção do futuro desejado.

Ressalta-se que a finalidade dos cenários não é a ação, mas, sim a compreensão do sistema, oferecendo uma visão a partir de 
elementos predeterminados e conexões entre as várias forças e eventos de condução do sistema (WACK, 1985, p. 78). Contudo, os objetivos da construção de cenários estão intimamente relacionados à IC: "minimizar os riscos ligados a ambientes em constante mudança; facilitar a definição de estratégias em um mundo cada vez mais incerto; auxiliar na construção do futuro desejado; e evitar ser surpreendido" (MARCIAL, 2011, p. 118).

\subsection{Monitoramento Informacional}

A atividade de inteligência vai além da cenarização, pois, após a identificação dos possíveis cenários, e tomada de decisão as organizações, criam se novos padrões e novos cenários, devendo, assim, monitorar os impactos da informação.

Monitorar o próprio ambiente e o ambiente externo é fundamental para 0 sucesso da estratégia tomada. $O$ termo monitoramento "designa uma técnica que tem como características principal a observação e coleta (monitoramento) de fatores científicos, telemáticos, tecnológicos e outros que possam afetar a organização de forma intensa." (TARAPANOFF, 1995, p. 40).

Monitoramento informacional é o método ou técnica de observação e acompanhamento constante de dados, informação e conhecimento relevantes ao negócio da organização e devem observar aspectos como usuários, foco, características marcantes, decisão, origem dos dados, canais, nível da informação, tipos de informações entre outros (VALENTIM; MOLINA, 2004).

Para Choo (1998) a "monitoração de ambientes organizacionais é a aquisição e uso de informação sobre eventos, tendências e relações em seu ambiente externo, cujo conhecimento auxiliará os gerentes a planejar as futuras ações." (apud MORESI, 2001, p.41).

Assim, o monitoramento de informação relevante à organização torna-se um grande desafio. Os executivos passam a necessitar de 
sistemas que identifiquem, monitorem coletem e analisem informações geradas no ambiente externo e sejam de interesse para o planejamento estratégico da organização (MOLINA; SALA, 2007, p. 66). Assim, Moresi (2001, p. 41) apresentou cinco passos distintos: a procura por recursos de informação; a seleção destes para monitorar; a identificação dos critérios de monitoração; a monitoração; e a determinação de ações especiais a serem tomadas em face dos resultados da monitoração.

Choo (1998) descreve alguns princípios para as melhores práticas de monitoramento: a) Planejar e gerenciar a monitoração como atividade estratégia,
como um programa de pesquisa e desenvolvimento;
b) Implementar a atividade como um sistema formal, planejado, continuo e coordenado;
c) Estabelecer parcerias com: especialistas em tecnologia da informação em projetar de monitoração, especialistas em determinados temas ou assuntos e peritos em informação;
d) Gerenciar a informação como uma função básica da monitoração (apud MORESI, 2001, p. 42).

\section{METODOLOGIA E PROCEDIMENTOS METODOLÓGICOS}

A pesquisa, quanto a sua natureza, pode ser enquadrada e em exploratória-descritiva. No que se refere à abordagem esta pesquisa enquadra-se qualitativa. Justifica-se esta abordagem, na presente pesquisa pelo fato de ser possível identificar atividades de inteligência que muitas vezes podem se desconhecidas pelos próprios atores envolvidos. Por fim, em relação às técnicas utilizadas neste trabalho será a pesquisa bibliográfica, a pesquisa documental e o estudo de caso.

Foi realizado um estudo a partir da Secretaria de Gestão e Planejamento do estado de Goiás (Segplan), com pesquisa documental disponibilizada pela secretaria por meio do site (sobre a secretaria, notícias, e nas bibliografias publicadas pela secretaria, como o plano Goiás 2030 e o Livro das realizações governamentais); e, entrevista com 
funcionários técnicos de planejamento, indicadas pelo superintendente da central de planejamento, e pela coordenação do NIPE, visado à identificação de atividades de inteligência, principalmente no que se refere à prospecção de cenários e monitoramento do estado de Goiás (GOIÁS, 2011a). Aqui se faz importante citar ações da Superintendência Central de Planejamento, principalmente no que se refere a atividades de inteligência e prospectiva, nas quais, pesquisou-se atividades de inteligência:

1. Plano estratégico do Governo do estado;

2. Planos Plurianuais;

3. Ações governamentais;

4. Políticas publicas;

5. Rede de planejamento, orçamento e gestão;

6. Portfólio de projetos estruturantes,

7. Fontes de recursos;

8. Inteligência estratégica;

9. Articulação e a integração dos órgãos/entidades do Governo;

10. Captação de recursos nacionais e internacionais;

11. Promover estudos e diagnosticar oportunidades e ameaças, visando a proposição de ações, enfatizando as regiões mais carentes e prioritárias;

12. Promover a divulgação das ações e resultados relativos ao planejamento das ações governamentais e projetos estruturantes (GOIÁS, 2011b).

Após isso, buscou-se identificar nas Secretarias de Ciência e Tecnologia (SECTEG), de Indústria e Comércio (SIC) e a de Segurança Publica (SSP) se nestas possuem outras atividades de inteligência. Adotou-se a mesma metodologia aplicada na Segplan, sendo que as pessoas entrevistadas foram funcionários da gerência de planejamento de cada secretaria.

A construção do questionário foi baseada nos princípios da ferramenta $5 \mathrm{~W}_{2} \mathrm{H}^{1}$, visando identificar atividades relacionadas no plano

\footnotetext{
Ferramenta utilizada para mapear atividades desenvolvidas por colaboradores de uma organização que visa responder: What - O que será feito (etapas); Why - Por que será feito (justificativa); Where - Onde será feito (local); When - Quando será feito (tempo); Who - Por
} 
Arielle Lopes de Almeida; João de Melo Maricato

Prospecção de cenários e monitoramento informacional como ferramentas de inteligência competitiva para o planejamento de políticas públicas no estado de Goiás

de ação das secretarias. Assim, no Quadro 1 são apresentadas as questões e objetivos levantados na pesquisa.

Quadro 1 - Questionário utilizado na pesquisa e objetivos a serem identificados

\begin{tabular}{|l|l|}
\hline QUESTÃO & OBJETIVOS \\
\hline $\begin{array}{l}\text { Quais as ações voltadas para a atividade de } \\
\text { prospectiva e monitoramento que são } \\
\text { desenvolvidas? } \\
\text { - Prospectiva de cenários a curto e médio } \\
\text { prazo; }\end{array}$ & $\begin{array}{l}\text { Identificar as atividades de prospectiva } \\
\text { e monitoramento. }\end{array}$ \\
$\begin{array}{l}\text { - Prospectiva de cenários a longo prazo; } \\
\text { - Monitoramento interno; }\end{array}$ & \\
\hline $\begin{array}{l}\text { Quais os resultados esperados destas } \\
\text { ações? }\end{array}$ & $\begin{array}{l}\text { Identificar o que se espera atingir com } \\
\text { as ações e auxiliar na identificação do } \\
\text { custo/benefício do plano. }\end{array}$ \\
\hline $\begin{array}{l}\text { Como estas ações são implementadas? } \\
\text { Identificar se as ações após } \\
\text { implementação utilizam atividades de } \\
\text { inteligência. }\end{array}$ \\
\hline $\begin{array}{l}\text { Quem são as pessoas envolvidas na } \\
\text { implementação e condução destas ações? }\end{array}$ & $\begin{array}{l}\text { Identificar se buscam parcerias externas } \\
\text { para visualizar o cenário. }\end{array}$ \\
\hline Onde as ações são desenvolvidas? & $\begin{array}{l}\text { Identificar se as ações vão além da } \\
\text { estrutura interna. }\end{array}$ \\
\hline Quando são realizadas estas ações? & $\begin{array}{l}\text { Identificar se as ações são continuas ou } \\
\text { não. }\end{array}$ \\
\hline O que se tem de recurso para estas ações? & $\begin{array}{l}\text { Auxiliar na identificação do } \\
\text { custo/beneficio }\end{array}$ \\
\hline
\end{tabular}

Fonte: Elaborado pelos autores.

\section{$5 \quad$ RESULTADOS E DISCUSSÕES}

Analisando os dados, buscou-se identificar quais eram as ações voltadas para a inteligência desenvolvidas pela Segplan. Identificou-se os planos plurianuais (elaborados para o período de cinco anos) constatando-se que a Segplan, em conjunto com as demais secretarias, realizam prospectivas de cenários que podem ser consideradas de curto e médio prazo. Como prospectiva de longo prazo, identificou-se, o Plano Goiás 2030 (realizado em 2010), no qual, há um estudo de cenários 
para 20 anos. No que se refere ao monitoramento, constata-se que, atualmente, é realizado pela Segplan em parceria com as demais secretarias, um monitoramento das atividades das secretarias, nomeado como Livro das Realizações Governamentais 2011-2013, além de relatórios anuais não publicados.

O Plano Goiás 2030 visa ser o referencial estratégico para os planejamentos a serem conduzidos por municípios, órgãos públicos, empresas privadas e entidades do terceiro setor, servindo de base para a construção e execução dos próximos Planos Plurianuais (PPA) e orçamentos estaduais. Ou seja, é utilizado para a prospecção de futuros possíveis e assessoramento oportuno às decisões da alta administração do estado, condizendo ao aspecto relevante da IC de ser um processo composto, apoiado por elementos culturais, comunicação organizacional, atividades de prospecção e monitoramento informacional e as tecnologias de informação e comunicação (VALENTIM, 2007, p. 22).

Porém, é importante indicar que o plano está inativo, contrariando um dos passos essenciais citados por Valentim (2002) que é criar mecanismos de feedback da geração de novos dados, informações e conhecimento para a retroalimentação do sistema. Assim, considera-se fundamental o monitoramento e avaliação das ações governamentais e políticas públicas para alcançar os resultados, aperfeiçoar a gestão governamental, aumentar a efetividade dos programas, bem como da necessidade de prestação de contas à sociedade goiana por parte do governo estadual através do Livro das Realizações Governamentais.

As ações indicadas do plano Goiás 2030 foram realizadas a partir do diagnóstico que contou com a participação de diversos grupos, resultando na identificação de temas estratégicos e respectivas incertezas críticas. Estas serviram de base para a elaboração dos cenários. Após este diagnóstico, foram criadas as hipóteses 
relacionadas às incertezas críticas e aplicado uma ferramenta de consulta pública, via internet, denominada "Áugures", que visou coletar percepções que possibilitassem a elaboração dos cenários prospectivos. As questões, nesta consulta, referiam-se às hipóteses mais prováveis e às hipóteses mais otimistas sobre o futuro do estado. Assim, foi possível observar interesse na criação de um cenário de referência; um cenário otimista; e, um cenário foco, sendo este último criado como um intermediário entre os cenários de referência e otimista. Estes são, respectivamente, os cenários apresentados por Godet (1993, p. 71), o cenário de referência, o cenário contrastado e o cenário desejável. Desse modo, esse instrumento pode ser considerado um elemento de IC adotado pelo estado de Goiás.

A elaboração do livro de Realizações Governamentais foi realizada a partir de informações oferecidas pelas próprias secretarias. Assim, foi possível identificar que o monitoramento foi realizado internamente pelas secretarias, sendo apenas agrupado na Segplan. Foi possível constatar que se trata de uma atividade interna de identificação das ações realizadas nas secretarias e não um monitoramento informacional propriamente dito. Conforme Choo (1998), o monitoramento é a aquisição e uso de informação relacionada ao seu ambiente externo, cujo conhecimento auxiliará os gerentes a planejar as futuras ações (apud MORESI, 2001, p. 41). A partir dessa análise, elaboração do livro de Realizações Governamentais não pareceu-nos poder ser categorizado em uma ação de IC.

Os órgãos envolvidos na criação e o local de execução, tanto do Plano Goiás 2030 como o Livro das Realizações Governamentais, são a Segplan juntamente com todas as secretarias. O Plano Goiás foi estruturado com o apoio do Núcleo de Inteligência e Prospectiva Estratégica (NIPE), criado pela Segplan e outros grupos que envolveriam todas as secretarias e a comunidade em geral, possibilitando uma maior interação e geração de indicadores e 
sinalizadores de futuro, contando com a comunidade em geral e/ou especializada.

O Plano Goiás 2030 foi realizado em 2010, visando planejar um o melhor cenário possível para 2030, com atualizações a partir de novos cenários possíveis. Já as atividades de monitoramento que existem atualmente são realizadas anualmente e ao final de governo durante todas as gestões do atual governo estadual, porém apenas na última gestão, o Livro das Realizações Governamentais, foi publicado.

Na elaboração do Plano Goiás, de acordo com a coordenadora do NIPE, foi gasto em torno de novecentos mil reais. Percebeu-se que o investimento está em consonância com o entendimento de que existe a necessidade de serviço de inteligência para o aperfeiçoamento de seus serviços e seu posicionamento em relação ao desenvolvimento tecnológico e à nova ordem internacional (QUEYRAS, QUONIAM, 2006, p. 94), porém, entende-se que ainda falta uma agregação de valor que auxilie na melhoria e consolidação dessas atividades e da aplicação dos recursos, uma vez, o plano ultrapassa de uma gestão para outra. O Livro foi realizado com os recursos humanos, físicos, e tecnológicos já existentes.

A partir deste estudo na Segplan, foram contatadas outras secretarias a fim de identificar se as mesmas realizavam algum trabalho de prospecção de futuro e monitoramento informacional. Optou-se em investigar mais a fundo as Secretarias de Ciência e Tecnologia (SECTEG), de Indústria e Comércio (SIC) e ade Segurança Publica (SSP), por julgar secretarias que demandariam forte atividade de inteligência, pois, entendeu-se que nestas secretarias existem variáveis e/ou atores que possam modificar significativamente estes cenários. Entendeu-se que estas são secretarias intensivas em informação e conhecimento.

Assim, na SECTEG identificou-se, como atividade de planejamento o Plano Plurianual e o monitoramento das ações do 
mesmo. Não obteve-se retorno quanto aos questionamentos SIC. Quanto à SSP constatou-se que existe relevantes atividades de inteligência.

Algumas ações voltadas para a atividade de prospectiva e monitoramento identificadas na SSP foram:

a. Prospectiva de cenários a curto e médio prazo: Plano plurianual

b. Prospectiva de cenários a longo prazo: cenários prospectivos com o Livro de Planejamento Estratégico 20122022

c. Monitoramento: o monitoramento de indicadores e sinalizadores deste plano.

Os resultados esperados por essas atividades são o de trabalhar antecipadamente todos os eventos da área de segurança, permitindo que seus membros enxergassem as dificuldades e os pontos fortes de cada estrutura, bem como, inúmeras possibilidades de melhoria. Organizar novos processos, construir novas possibilidades de ação e buscar a excelência na prestação de serviços à comunidade. Assim, confirma-se que há prospecção de cenários, a qual é construía para "apoiar o processo de planejamento estratégico e servem como orientadores do processo de monitoramento, indicando as principais questões e atores e serem acompanhadas." (MARCIAL, 2011, p. 40).

A primeira etapa desse processo foi a integração de todos os órgãos que compõem a Segurança Pública em Goiás promovendo uma tempestade de ideias que, depois de analisadas e registradas nesses produtos estratégicos. Entende-se que a organização possua um sistema de uso da informação baseada em três processos: a criação de significado, construção do conhecimento e tomada de decisões, integrando um clico de interpretação, aprendizado e ação ( $\mathrm{CHOO}$, 2003). Constatou-se que a SSP criou um Grupo de Controle do Planejamento Estratégico que receberam treinamentos para a construção do Plano Estratégico da Segurança Pública. Utilizaram o 
"Método Grumbach", integrado pela aplicação do software Brainstormingweb, que possibilita a priorização e sincronização das iniciativas estratégicas para posterior gerenciamento de projetos e monitoramento de indicadores de desempenho, traduzindo-se em um planejamento e gestão orientados para resultados.

Dessa forma, foi possível a implantação de um sistema de gestão com uma estruturação lógica de causa e efeito, através da interação dos objetivos e iniciativas estratégicas, que determinará um grupo coerente de indicadores, para obter, como produto final, a consecução das estratégias de atuação e, por consequência, alcançar os objetivos de resultado (perspectiva da sociedade), em atendimento à missão da Instituição.

As pessoas envolvidas na implementação e condução destas ações são todos os órgãos que compõem a Segurança Pública em Goiás, visando a implantação em todo o estado de Goiás.

O plano teve inicio em 2012, porém, somente neste momento está sendo implantado, portanto, não há como identificar-se a periodicidade das ações. Porém, através do plano pode-se identificar que os envolvidos tem a ciência que o ambiente informacional está arraigado no ambiente organizacional, e ambos são afetados pelo ambiente externo da empresa (DAVENPORT, 2001). E quanto ao valor do projeto, constatou-se que foi elaborado em parceria da iniciativa privada, desse modo, sem ônus para o Estado.

\section{CONCLUSÃO}

O futuro não pode ser previsto em sentido estrito, mas, a análise de informações pode ser utilizada para prospecta-lo e monitora-lo, pois, são ferramentas importantes para auxiliar no processo de tomada de decisão, com o propósito de identificar oportunidades e reduzir os riscos. 
O monitoramento de indicadores é fundamental para efetuar o alinhamento estratégico, ou seja, e apoiar as atividades de Inteligência Estratégica. E, esta tem como propósito o acompanhamento das variáveis e dos atores que impactam nos cenários e nos objetivos de resultado, antecipando mudanças, neutralizando as ameaças e potencializando as oportunidades.

Assim, foi possível identificar que o estado de Goiás, em suas secretarias, não existe um processo unificado de prospecção e monitoramento. Investe-se em inteligência, porém, não foram percebidas consistentes atividades de inteligência e construção de cenários. Entende-se, porém, que o caso da Secretaria de Segurança Pública está em um estágio mais avançado de desenvolvimento.

Seria importante o estado assumir uma postura proativa, ou seja, relacionada ao planejamento futuro, ou seja, planejar a construção de futuros alternativos para o estado. Porém, a partir dos resultados, entende-se que a afirmativa de Aun (2003) faz todo o sentido. Ou seja, parece que as atividades relacionadas à IC em organizações públicas são tomadas como ações de interesses políticos individuais ao invés de coletivos.

Mesmo que as secretarias sigam o plano plurianual, realizado com a parceria da Segplan, entende-se que não há uma coordenação efetiva e integrada das atividades, e o trabalho acaba sendo realizado de maneira isolada. As secretarias parecem sentir a necessidade de contratação de empresas terceirizadas para auxiliar no planejamento. Entende-se que, devido importância de uma atividade de inteligência, poderia haver uma equipe dentro da Secretaria de Gestão e Planejamento.

Tendo em vista os resultados obtidos na presente pesquisa e, também pelas suas limitações, sugere-se que sejam desenvolvidas pesquisas futuras para a melhor compreensão do cenário apresentado, em especial quanto as atividades de inteligência no âmbito da 
administração pública. Dentre as sugestões, considera-se relevante o estudo das possibilidades de se agregar valor a informação prospectada e monitorada, visando compreender o interesse e usos destas ferramentas para a administração pública; a identificação e análise de tecnologias de informação e comunicação para a atividade de prospecção de monitoramento na administração pública; e, o estudo da confiabilidade das informações de prospecção de monitoramento na administração pública.

\section{REFERÊNCIAS}

AUN, Marta P. Políticas públicas de informação e desenvolvimento. In.: PAIM, Isis (Org.). A gestão da informação e do conhecimento. Belo Horizonte: ECl - UFMG, 2003. Cap.3, p. 55-90.

BATISTA, Fabio Ferreira. O governo que aprende: implementando a gestão do conhecimento no executivo federal. In.: STAREC, Claudio; GOMES, Elisabeth Braz Gomes; CHAVES, Jorge Bezerra Lopes.

Gestão estratégica da informação e inteligência competitiva. São Paulo: Saraiva, 2006. p. 185-194.

BRASIL. Decreto no 4.376, de 13 de setembro de 2002. Dispõe sobre a organização e o funcionamento do Sistema Brasileiro de Inteligência, instituído pela Lei no 9.883, de 7 de dezembro de 1999, e dá outras providências. Disponível em:

<http://www.planalto.gov.br/ccivil_03/decreto/2002/d4376.htm>. Acesso em: 11 abr. 2014.

$\mathrm{CHOO}$, WeiChun. A organização do conhecimento: como as organizações usam a informação para criar significado, construir conhecimento e tomar decisões. São Paulo: Senac, 2003.

COSTA, E. A. Análise do ambiente externo. In: Gestão estratégica: da empresa que temos para a empresa que queremos. 2. ed. São Paulo: Saraiva, 2007. Cap. 3.

CRISTO, Carlos Manuel Pedroso Neves. Prospectiva estratégica: instrumento para a construção do futuro e para a elaboração de políticas públicas. Revista do Serviço Público, Brasília, v. 54, n. 1, p. 63-78, 2014. 
DAVENPORT, Thomas $\mathrm{H}$. Ecologia da informação: por que só a tecnologia não basta para o sucesso na era da informação. São Paulo:

Futura, 2001.

FLEISHER, Craig S. An introduction to the management and practice of competitive intelligence. In: FLEISHER, Craig S.; BLENKHORN, David. L. (Org.). Managing frontiers in competitive intelligence. Westport: Quorum, 2001. p. 3-18.

GUEDES, Isabela Assis; CÂNDIDO, Gesinaldo Ataíde. Modernização administrativa no setor público: utilização de tecnologias de gestão e de informação para o gerenciamento do conhecimento. Revista Gestão.Org, Recife, v. 6, n. 2, 2010.

GODET, Michel. Método e cenários. In: Manual de prospectiva estratégica: da antecipação à ação. Lisboa: Publicações Dom Quixote, 1993. Cap. 1.

GOIÁS (Estado). Secretaria de Gestão e Planejamento. Plano Goiás 2030: uma nova visão do estado. Goiânia: SEGPLAN, 2011a. Disponível em: <http://www.sagres.org.br/artigos/nipe/plano_goias_2030.pdf>. Acesso em: 11 de abr. 2014.

GOIÁS (Estado). Superintendência Central de Planejamento.

Atribuições. 2011b. Disponível em:

<http://www.segplan.go.gov.br/post/ver/122348/superintendenciacentralde-planejamento_>. Acesso em: 21 de jul. 2014

MACEDO, Daniela Luiza; RODRIGUES, Leonel Cezar; SILVEIRA, Amélia. Sistema de Inteligência Acadêmica na gestão da PósGraduação Stricto Sensu em Administração. Revista de Ciências da Administração, Florianópolis, v. 13, n. 31, p. 136-160, 2011.

MARCIAL, Elaine. Análise estratégica: estudos de futuro no contexto da inteligência competitiva. Brasilia: Thesaurus, 2011. 268 p. (Coleção inteligência competitiva; v. 2).

MOLINA, Letícia Gorri; SALA, Fabiana. Prospecção e monitoramento informacional no processo de inteligência competitiva organizacional. In: VALENTIM, Marta Lígia Pomim (Org.). Informação, conhecimento e inteligência organizacional. 2. ed. Marília: Fundep, 2007.

MORESI, Eduardo Amadeu Dutra. Inteligência organizacional: um referencial integrado. Ciência da Informação, Brasília, v. 30, n. 2, maio/ago. 2001. Disponível em: <http://www.scielo.br/pdf/ci/v30n2/6210.pdf>. Acesso em: 11 abr. 2014. 
PLATT, W. A produção de informações estratégicas. Rio de Janeiro: Biblioteca do Exercito, 1974.

PORTER, Michael E. Cenários industriais e estratégia competitiva sob incerteza. In: Vantagem competitiva: criando e sustentando um desempenho superior. 15. ed. Rio de Janeiro: Campus. 1989.

QUEYRAS, Joachim; QUONIAM, Luc. Inteligência competitiva. In: TARAPANOFF, Kira (Org.). Inteligência, informação e conhecimento. Brasilia: IBICT, UNESCO, 2006. p. 73-98.

ROEDEL, Daniel. Estratégia e inteligência competitiva. In: STAREC, Claudio; GOMES, Elisabeth Braz Gomes; CHAVES, Jorge Bezerra Lopes. Gestão estratégica da informação e inteligência competitiva. São Paulo: Saraiva,2006. p. 67-86.

SILVA, Anielson Barbosa. A gestão de sistemas organizacionais em ambientes turbulentos. In: STAREC, Claudio; GOMES, Elisabeth Braz Gomes; CHAVES, Jorge Bezerra Lopes. Gestão estratégica da informação e inteligência competitiva. São Paulo: Saraiva, 2006. p. 195-210.

TARAPANOFF, Kira. Prospecção. In.: Técnicas para a tomada de decisão nos sistemas de informação. 3. ed. Brasília: Thesaurus, 1995.

TARAPANOFF, Kira (Org.). Inteligência, informação e conhecimento. Brasilia: IBICT, UNESCO, 2006.

VALENTIM, Marta Ligia Pomim. Inteligência competitiva em organizações: dado, informação e conhecimento. DataGramaZero, Rio de Janeiro, v. 3, n. 4, ago. 2002.Disponivel em:

<http://www.dgz.org.br/ago02/Art_02.htm>. Acesso em: 11 abr. 2014.

VALENTIM, Marta Lígia Pomim et.al. O processo de inteligência competitiva em organizações. DataGramaZero, Rio de Janeiro, v. 4, n. 3, jun. 2003. Disponivel em: <http://www.dgz.org.br/jun03/Art_03.htm>. Acesso em: 11 abr. 2014.

VALENTIM, Marta Lígia Pomim (Org.). Informação, conhecimento e inteligência organizacional. 2. ed. Marília: Fundep, 2007.

VALENTIM, Marta Lígia Pomim; MOLINA, Letícia Gorri. Prospecção e monitoramento informacional no processo de inteligência competitiva. Encontros Bibli, Florianópolis, n. esp., 2004. Disponível em: <http://www.encontrosbibli.ufsc.br/bibesp/esp_01/sumarioes .htm>. Acesso em: 11 abr. 2014. 
WACK, Pierre. Scenarios: uncharted waters ahead. Harvard Business Review, p. 72-89, Sept./Oct. 1985. Disponível em: <http://www.damianbrunold.ch/files/ testing/Wack.pdf>. Acesso em: 11 abr. 2014.

WAGNER, Ben R. Can competitive intelligence be effectively applied to public-sector organizations? In: FLEISHER, Craig S.; BLENKHORN, David. L. (Org.). Controversies in competitive intelligence: the enduring issues. Westport: Praeger, 2003. p. 70-82.

\section{Title}

Prospecting scenarios and information scanning as competitive intelligence tools for policy planning in the state of Goiás

\section{Abstract}

Introduction: Strategic intelligence is a continuous process related to information, aimed at identifying their relationships and connections to build future scenarios in order to minimize risks and thoughtless actions. The information environment is important to obtain, create, share and internalize knowledge for private and public sector.

Objectives: The aim of the research paper is to identify if intelligence activities used for planning the activities and operations of the State of Goiás.

Methods: The methodological procedures used in bibliographics research and interview. This is a case study, supported in a descriptive qualitative research. It identifies and analyzes intelligence activities used in the departments of Management and Planning, Industry and Commerce and Public Safety.

Resultados: It was found that there is no unified process of exploration and monitoring in the state of Goiás. There are investments in intelligence, however, they are not effectively employed or well managed.

Conclusion: Although strategic intelligence serves as guideline of exploration and scanning process. This research indicates the main scenarios to be followed in public administration in the state of Goiás, however, there are gaps in their implementation.

Keywords: Strategic Intelligence. Government planning. State of Goiás. Informational environment. Prospecting scenarios. Information scanning. 
Arielle Lopes de Almeida; João de Melo Maricato

Prospecção de cenários e monitoramento informacional como ferramentas de inteligência competitiva para o planejamento de políticas públicas no estado de Goiás

\section{Titulo}

Prospección Escenarios Y Monitoreo De Información Como Herramientas De Inteligencia Competitiva Para La Planificación De Política En El Estado De Goiás

\section{Resumen}

Introducción: La inteligencia estratégica debe ser vista como un proceso continuo de información que tiene como objetivo identificar las relaciones y conexiones para construir escenarios de futuro con el fin de minimizar los riesgos y acciones irreflexivas. Reconoce la importancia de un entorno de información dirigida a la obtención, la creación, el intercambio y la internalización de los conocimientos, incluido el sector público.

Objectivo: El objetivo es identificar las actividades de inteligencia que están siendo utilizados para la planificación del estado de Goiás.

Metodología: Se utiliza como instrumentos de investigación bibliográfica y entrevistas. Identifica y analiza las actividades de inteligencia utilizados en los departamentos de Gestión y Planificación, Industria y Comercio, y Seguridad Pública.

Resultados: Se encontró que en el estado de Goiás no existe un proceso unificado de exploración y monitoreo. Hay inversiones en actividades de inteligencia, pero éstos no se aplican eficazmente o bien administrados.

Conclusión: Aunque la inteligencia estratégica servir como guía la exploración y el proceso de monitoreo. Indica los principales escenarios que se deben seguir en la administración pública, el estado de Goiás, hay lagunas en su uso.

Palabras Clave: Inteligencia Estratégica. Planificación del Gobierno. Estado de Goiás. Entorno informativo. Prospección escenarios. Monitoreo informativo.

Recebido em: 09/09/2014

Aceito em: 26/06/2015 